\title{
A non-metallic additive for diamond-wire-sawn multi-crystalline silicon texturing
}

\author{
He Wang ${ }^{1,2, a}$, Chunlan Zhou ${ }^{1,2, b^{*}}$, Wenjing Wang ${ }^{1,2}$ \\ ${ }^{1}$ Key Laboratory of Solar Thermal Energy and Photovoltaic System of Chinese Academy of Sciences, Institute of Electrical Engineering, \\ The Chinese Academy of Sciences, Beijing, China 100190 \\ ${ }^{2}$ University of Chinese Academy of Sciences, Beijing, China 100049
}

\begin{abstract}
Diamond-wire-sawn (DWS) technology has been widely used in the photovoltaic industry. When using the $\mathrm{HF} / \mathrm{HNO}_{3} / \mathrm{H}_{2} \mathrm{O}$ acid etching solution for texturing of DWS multi-crystalline silicon(mc-Si), the aid of additive is required to improve the reactivity of the mc-Si surface in the acid texturing solution. It also needs to enhance the nucleation and uniform growth of the texturing surface. This paper proposes a nonmetallic additive for DWS mc-Si texturing. Sodium polyacrylate is added to the $\mathrm{HF} / \mathrm{HNO}_{3} / \mathrm{H}_{2} \mathrm{O}$ acid etching solution to reduce the reflectance of DWS mc-Si and improve surface morphology. Compared to the textured wafers without additive, the surface of the wafers using this method is uniformly distributed with pits whose size is $0.5 \mu \mathrm{m} \times 1 \mu \mathrm{m}$. And the weighted average reflectance of the textured wafers can be reduced from $33.32 \%$ to $23.9 \%$ in the wavelength range of $350-1100 \mathrm{~nm}$, with the lowest reflectance of $19.8 \%$ reached at $950 \mathrm{~nm}$. It shows a promising application prospect.
\end{abstract}

\section{Introduction}

Diamond-wire-sawn (DWS) technology has replaced slurry-wire-sawn(SWS) technology because of low sawing loss, fast speed and environmental protection. However, for multi-crystalline silicon (mc-Si), the repetitive motion of diamond wires leads to obvious line marks on the wafer surface and hinder the texture ${ }^{[1]}$. In addition, the lack of defect positions which provide starting points for $\mathrm{HF} / \mathrm{HNO}_{3} / \mathrm{H}_{2} \mathrm{O}$ system leads to high reflectance, resulting in the low efficiency of mc-Si solar cells $^{[2]}$.

There are two main texturing methods for DWS mc$\mathrm{Si}$ : dry texturing and wet texturing. The dry texturing method mainly includes femtosecond laser etching and reactive ion etching. The weighted average reflectance of the wafer after dry texturing can be less than $5 \% 0^{[3-5]}$. However, the strict requirements and expensive equipment of dry texturing inhibit its scale application. Wet texturing mainly includes metal assisted chemical etching (MACE). MACE takes metal nanoparticles as catalysts for redox reactions during acid etching to promote the dissolution of silicon in $\mathrm{HF} / \mathrm{HNO}_{3} / \mathrm{H}_{2} \mathrm{O}$ system. Nanowire arrays are formed on the surface, and the reflectance is less than $10 \%$ after MACE ${ }^{[6,7]}$. However, there are still metal particles on the bottom of these texturing surfaces of the silicon wafer, which require extra cleaning process to remove. Moreover, MACE requires $\mathrm{NaOH}$ solution for pore expansion to reduce the surface area of nanostructured silicon for surface passivation, which making the weighted average reflectance up to $20 \%{ }^{[8]}$.

aemail: wanghe@mail.iee.ac.cn

*corresponding author: bemail: zhouchl@mail.iee.ac.cn
In this paper, an efficient, low-cost and low wafer loss method is proposed for DWS mc-Si texturing. In experiments, sodium polyacrylate was added to the solution of $\mathrm{HF} / \mathrm{HNO}_{3} / \mathrm{H}_{2} \mathrm{O}$. This method has a high degree of compatibility with existing acid texturing lines, does not require additional steps and is highly safe. The wafers obtained in laboratory achieved the weighted average reflectance of $23.9 \%$, while the surface weighted average reflectance of the textured wafers without additives was $33.32 \%$. The surface of the wafers using sodium polyacrylate is uniformly distributed with pits whose size is $0.5 \mu \mathrm{m} \times 1 \mu \mathrm{m}$. The experiment results show that this is a promising research.

\section{Materials and Methods}

The experiments were conducted with P-type 156 $\mathrm{mm} \times 156 \mathrm{~mm}, 180 \mathrm{~mm}$ thick, the resistivity of $1 \Omega \cdot \mathrm{cm}$ DWS mc-Si wafers. Metallic impurities were removed from silicon wafer surface by Radio Corporation of America (RCA) cleaning. Then the silicon wafers were sawn into small slices of $25 \mathrm{~mm} \times 25 \mathrm{~mm}$ by a laser. HF $(40$ wt.\%), $\mathrm{HNO}_{3}(69$ wt.\%) and deionized (DI) water were mixed in a volume ratio of $1: 1: 1$ to form the conventional acid solution with the volume of each component solution was $30 \mathrm{ml}$ in experiments. An amount of 50\% sodium polyacrylate aqueous solution was added to the conventional acid solution. The temperature of the entire acid solution was maintained at $15{ }^{\circ} \mathrm{C}$ by a constant temperature water bath. After the acid etching, the residual acid solution on the silicon wafer surface was removed by cleaning with DI water. To enlarge the size of 
pits on the wafer surface, these samples were etched in $\mathrm{NaOH}(1 \mathrm{wt} . \%)$ solution for $1 \mathrm{~min}$. The temperature of the entire $\mathrm{NaOH}$ solution was maintained at $20{ }^{\circ} \mathrm{C}$ by a constant temperature water bath. Finally, these samples were cleaned with DI water and dried by nitrogen gas.

The reflectance of samples was measured in the range of 350-1100 nm by a UV-VIS-NIR spectrophotometer. The morphology and structure of samples were observed by field emission scanning electron microscopy (SEM).

\section{Result and Discussion}
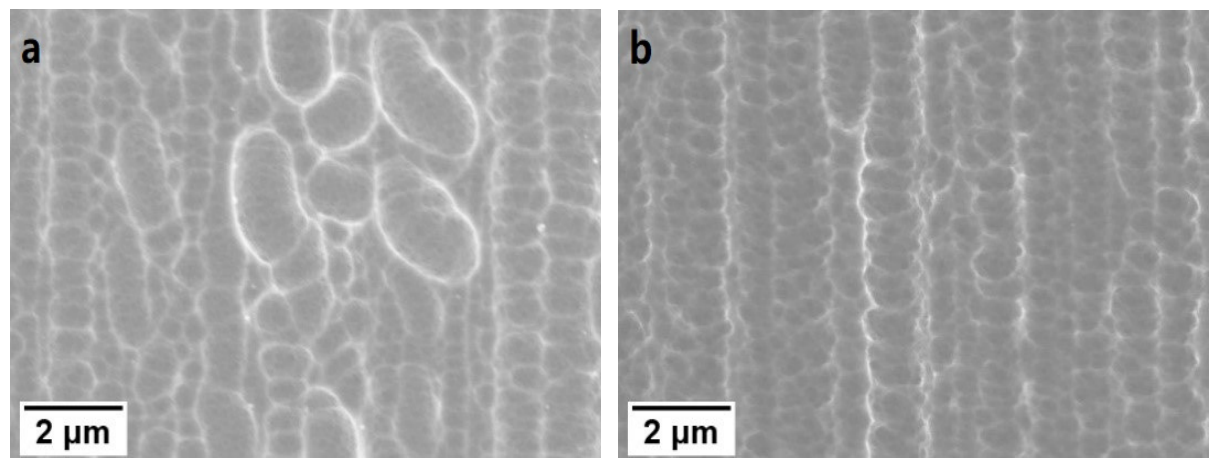

Fig. 1 SEM image of DWS mc-Si wafers etched by different solution for 3 min and $\mathrm{NaOH}$ solution for 1 min (a)conventional acid solution (b)acid solution with $0.6 \mathrm{~g}$ sodium
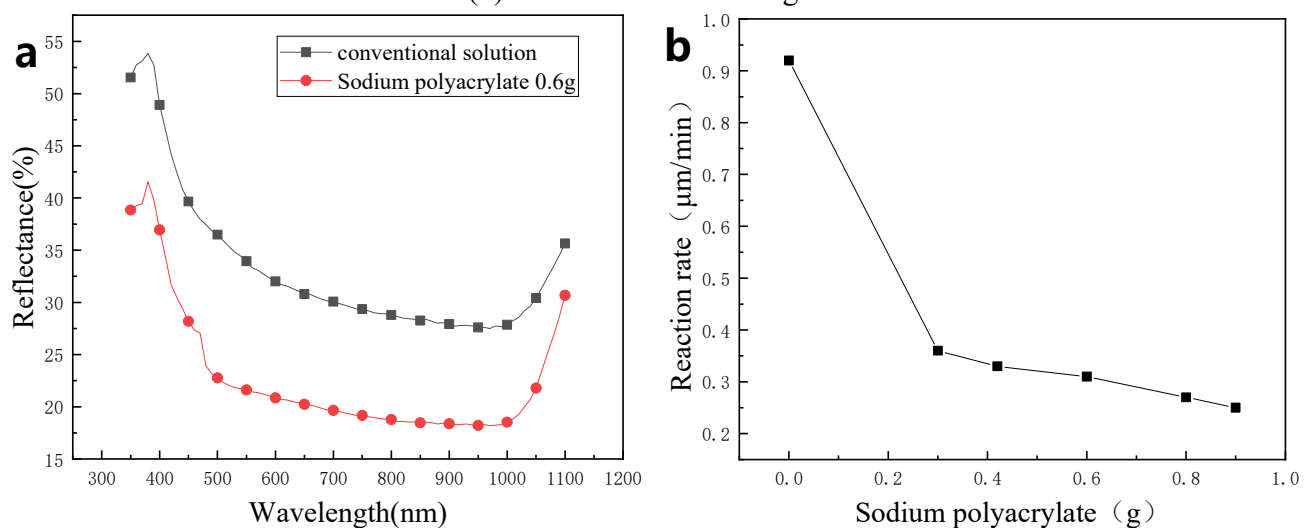

Fig. 2 (a)The reflectance spectra of the DWS mc-Si wafers etched by conventional solution or sodium polyacrylate solution for 3 min and $\mathrm{NaOH}$ solution for $1 \mathrm{~min}$

(b) Effect of sodium polyacrylate addition on reaction rate
Fig. 2 (a)shows that the surface reflectance of the wafers textured without additives in acid solution is higher than $30 \%$ in the range of $350-1100 \mathrm{~nm}$. Adding 0.6 g 50\% sodium polyacrylate aqueous solution in conventional acid solution, the surface reflectance is greatly reduced, with the lowest reflectance of $19.8 \%$. The main reason is that the texturing structure is tinier, which increase the multiple reflections of the light path and enhance the light trapping. In conventional acid solutions without additives, the silicon wafers do not make good contact with the reaction solution due to the hydrophobicity of silicon. And the lack of defective spots on the surface of DWS mc-Si for the reaction leads to inadequate starting points for etching. In addition, the reaction of silicon with acid is fast, and the size of the texturing structure is relatively large. The addition of sodium polyacrylate reduces the surface tension of the with it and creating finer bubbles during etching process. acid solution, bringing the silicon wafer into full contact with uneven size pits after conventional acid solution hing for 3 min and $\mathrm{NaOH}$ solution for $1 \mathrm{~min}$. Small pits $0.5 \mu \mathrm{m} \times 1 \mu \mathrm{m}$ are partially distributed on the surface. sawing line marks. In addition, there are many large pits wich are 1-2 $\mu \mathrm{m}$ wide and about $3 \mu \mathrm{m}$ long. Wafer distributed with uniform pits after acid solution with $0.6 \mathrm{~g}$ sodium polyacrylate etching for $3 \mathrm{~min}$ and $\mathrm{NaOH}$ solution etching for $1 \mathrm{~min}$. The size of these pits is basically $0.5 \mu \mathrm{m} \times 1 \mu \mathrm{m}$, as shown in Fig. 1(b).
Fig. 1(a) shows DWS mc-Si wafer surfaces are distributed These pits are arranged linearly due to the effect of DWS

Sodium polyacrylate makes it possible for the bubbles generated by the reaction to escape quickly from the surface of the wafer. Bubbles do not adhere to the surface or prevent subsequent etching, thus ensuring that the reaction rate is not too slow. The quality of the silicon loss is obtained by measuring the quality of the silicon before and after the texturing. In the same condition, the wafers loss textured by sodium polyacrylate solution are nearly half of those textured by conventional solution, indicating that sodium polyacrylate reduces the rate of acid etching. Too fast reaction rate is not conducive to the control of the reaction, resulting in poor reproducibility of texturing. The addition of sodium polyacrylate improves the controllability of the reaction.

In order to investigate the effect of sodium polyacrylate addition on the reaction rate, morphological appearance and reflectance of the wafers, sodium polyacrylate solutions of different weights were added to the conventional acid solution under the conditions of fixed ratio and volume of acid solution and reaction time. 
Fig. 2(b) shows the effect of different sodium polyacrylate additions on the reaction rate for $3 \mathrm{~min}$ of acid etching and $1 \mathrm{~min}$ of $\mathrm{NaOH}$ etching. The reaction rate is expressed by the etching thickness per min on each side of the silicon wafer of the acid solution. It is clear that the rate of the reaction decreases rapidly when sodium polyacrylate is added to a conventional acid solution without additives. The rate of reaction decreases linearly with increasing addition of sodium polyacrylate and the decrease is relatively slight. When $0.6 \mathrm{~g}$ sodium polyacrylate is used for texturing, the thickness of the wafer etched on each side is $1.02 \mu \mathrm{m}$, which is much less than the thickness of $5.5 \mu \mathrm{m}$ etched by conventional texturing additives, and the loss of silicon is much less.

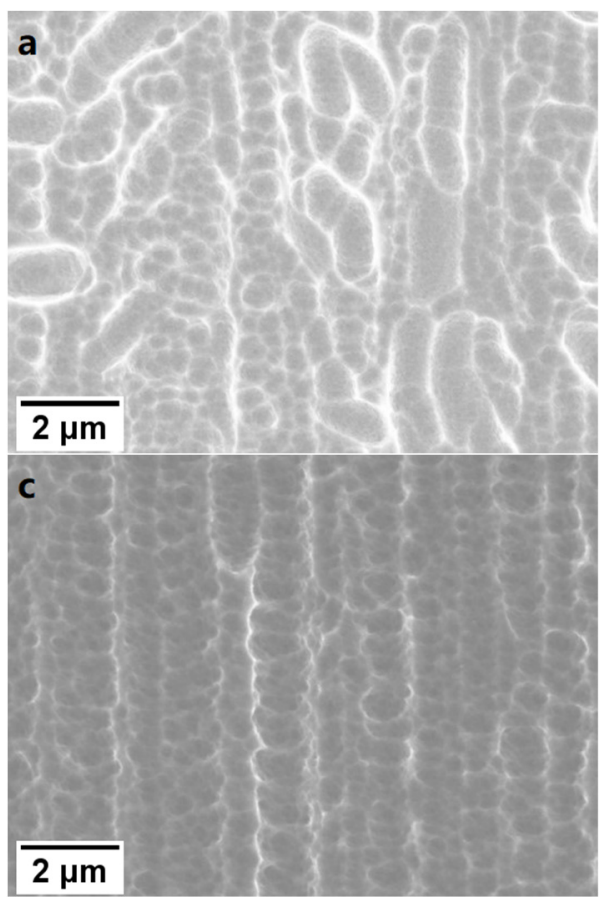

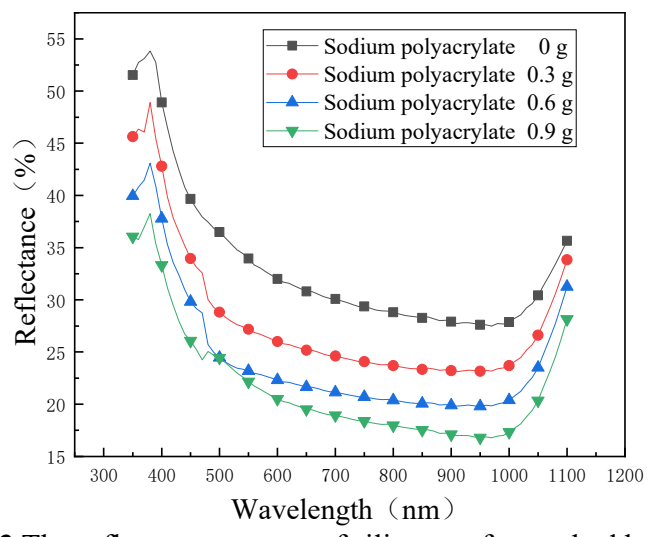

Fig. 3 The reflectance spectra of silicon wafers etched by acid solution with different amounts of sodium polyacrylate for 3 min and $\mathrm{NaOH}$ solution for $1 \mathrm{~min}$

Fig. 3 shows the effect of different amounts of sodium polyacrylate on the reflectance of silicon wafers etched by acid solution for $3 \mathrm{~min}$ and $\mathrm{NaOH}$ solution for $1 \mathrm{~min}$. The amount of sodium polyacrylate in the acid solution gradually increased from 0 to $0.9 \mathrm{~g}$. It is clear that when the addition of sodium polyacrylate increases, the reflectance of the textured wafer gradually decreases.

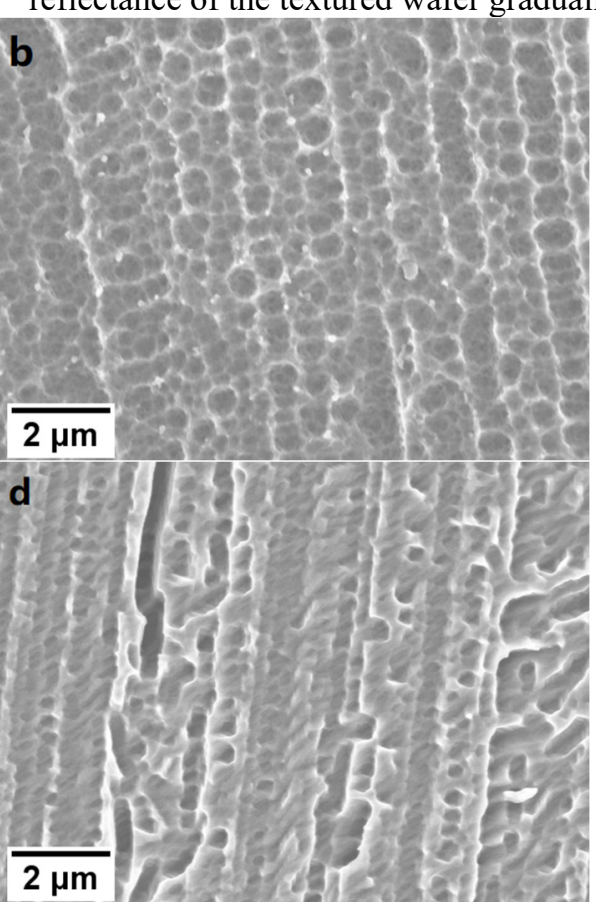

Fig. 4 SEM images of DWS mc-Si wafers etched by acid solution with different amounts of sodium polyacrylate for 3 min and $\mathrm{NaOH}$ solution for $1 \mathrm{~min}(\mathrm{a}) 0 \mathrm{~g}(\mathrm{~b}) 0.3 \mathrm{~g}(\mathrm{c}) 0.6 \mathrm{~g}(\mathrm{~d}) 0.9 \mathrm{~g}$

As shown in Fig. 4(a), the surface of the wafer etched without the addition of sodium polyacrylate is covered with unevenly distributed pits. As shown in Fig. 4(b), when the amount of sodium polyacrylate added is $0.3 \mathrm{~g}$, uniformly sized pits appear on the surface of the silicon wafer, but the surface of the pits is relatively rough and there are even smaller pits in the pits. The depth of the pits is relatively shallow, resulting in still higher reflectance. As shown in Fig. 4(c), when the amount of sodium polyacrylate added is $0.6 \mathrm{~g}$, the surface of silicon wafer is uniformly distributed with $0.5 \mu \mathrm{m} \times 1 \mu \mathrm{m}$ pits, and the surface of the pits is smooth. The damage layer caused by
DWS on the wafer surface is completely removed. However, as shown in Fig. 4(d), when the addition of sodium polyacrylate reaches $0.9 \mathrm{~g}$, the textured silicon wafer surface does not completely form a velvet surface but remains many long, deep grooves. Due to the addition of sodium polyacrylate, the reaction rate of etching is reduced and do not completely remove the damage layer caused by DWS on the wafer surface. Therefore, the amount of sodium polyacrylate added should be no more than $0.6 \mathrm{~g}$ to ensure that the surface damage layer is completely removed. 

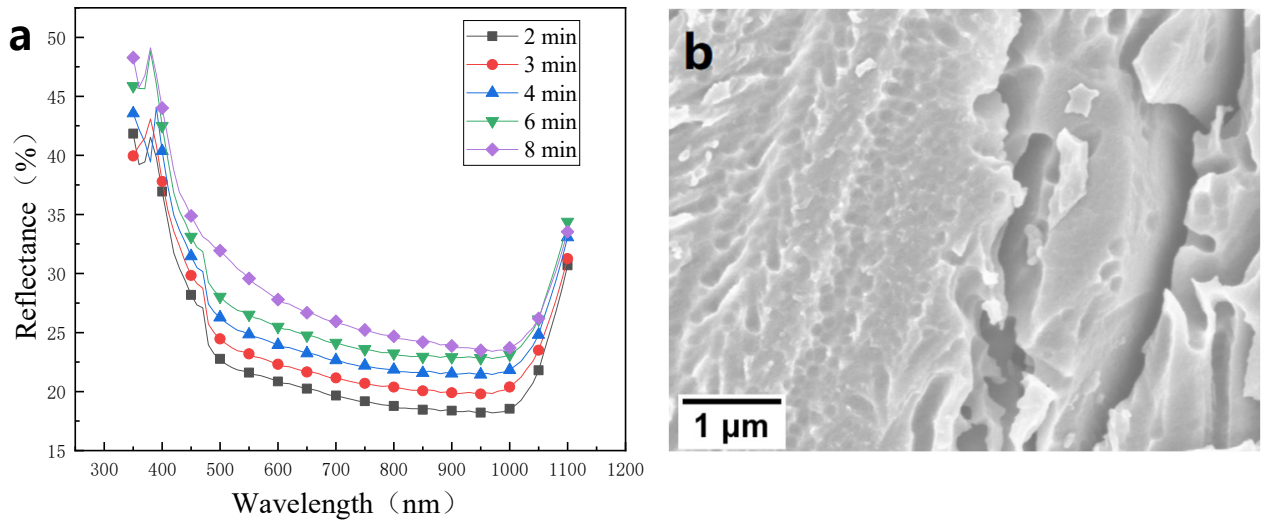

Fig. 5 (a)The reflectance spectra of DWS mc-Si wafers etched by acid solution with $0.6 \mathrm{~g}$ sodium polyacrylate for different time and $\mathrm{NaOH}$ solution for $1 \mathrm{~min}$

(b)SEM image of DWS mc-Si wafers etched by acid solution with $0.6 \mathrm{~g}$ sodium polyacrylate for 2 min and $\mathrm{NaOH}$ solution for $1 \mathrm{~min}$

Fig. 5(a) shows the effect of acid solution etching time on the reflectance with $0.6 \mathrm{~g}$ sodium polyacrylate and $\mathrm{NaOH}$ solution etching for $1 \mathrm{~min}$. The reflectance gradually increases with the increase of the reaction time when the acid texturing time is 2 to $8 \mathrm{~min}$. As shown in Fig. 5(b), there are a large number of damage layers caused by DWS on the wafer surface, although the reflectance is low when etching for $2 \mathrm{~min}$ in acid solution with $0.6 \mathrm{~g}$ sodium polyacrylate and etching for $1 \mathrm{~min}$ in $\mathrm{NaOH}$ solution. The surface of these damaged areas is smooth, and there are strip pits with larger depth and larger surface area than those obtained by texturing. The smaller pits obtained by inadequate reaction and deep pits in the DWS damage area result in low reflectance. The presence of these deep pits causes severe surface recombination, which prevent the improvement the solar cell efficiency. As shown in Fig. 4(c), the surface of the wafer with acid etching for $3 \mathrm{~min}$ has no damage layer and uniformly distributed $0.5 \mu \mathrm{m} \times 1 \mu \mathrm{m}$ pits. Therefore, the acid etching time of $3 \mathrm{~min}$ is suitable in the condition of using $0.6 \mathrm{~g}$ of sodium polyacrylate.

\section{Conclusions}

Based on the $\mathrm{HF} / \mathrm{HNO}_{3} / \mathrm{H}_{2} \mathrm{O}$ etching system, this paper studies the effect of sodium polyacrylate on the reflectance and surface morphology of DWS mc-Si. The reflectance of the silicon wafer surface was higher than $30 \%$ in the range of $350-1100 \mathrm{~nm}$ after using $\mathrm{HF} / \mathrm{HNO}_{3} / \mathrm{H}_{2} \mathrm{O}$ acid solution for texturing. The size of the pits on the silicon wafer surface was not uniform, and there were small pits of $0.5 \mu \mathrm{m} \times 1 \mu \mathrm{m}$ and a large number of large pits of $2 \mu \mathrm{m} \times 3 \mu \mathrm{m}$. The addition of sodium polyacrylate reduces the surface tension of the acid solution, so that silicon and the solution are fully contacted, thus increasing the number of starting points for etching. It also reduces the reaction rate and increases the controllability of the etching process. Considering the surface reflectance and texturing time, the optimum reaction conditions are as follows: the addition of sodium polyacrylate is $0.6 \mathrm{~g}$, the etching time of acid solution is 3 min, and the etching time of $\mathrm{NaOH}$ solution is $1 \mathrm{~min}$.

\section{Acknowledgments}

The project 61874120 granted by National Natural Science Foundation of China.

\section{References}

1. CHEN W, LIU X, LI M, et al. On the nature and removal of saw marks on diamond wire sawn multicrystalline silicon wafers[J]. Materials Science in Semiconductor Processing, 2014, 27: 220-227. DOI:10.1016/j.mssp.2014.06.049.

2. SOPORI B, DEVAYAJANAM S, BASNYAT P, et al. Surface damage introduced by diamond wire sawing of si wafers: measuring in-depth and the lateral distributions for different cutting parameters[J]. MRS Online Proceedings Library, 2015, 1770(1): 61-66. DOI:10.1557/opl.2015.830.

3. YOO J, YU G, YI J. Large-area multicrystalline silicon solar cell fabrication using reactive ion etching (rie) $[\mathrm{J}]$. Solar Energy Materials and Solar Cells, 2011, 95(1): 2-6. DOI:10.1016/j.solmat.2010.03.029.

4. DING J, ZOU S, CHOI J, et al. A laser texturing study on multi-crystalline silicon solar cells[J]. Solar Energy Materials and Solar Cells, 2020, 214: 110587. DOI:10.1016/j.solmat.2020.110587.

5. LU W, QIU X, ZHAO Q, et al. Enhanced optoelectronic conversion in diamond-wire sawing multi-crystalline silicon solar cells through nanotexture-induced photon management $[\mathrm{J}]$. Solar Energy Materials and Solar Cells, 2018, 185: 439444. DOI:10.1016/j.solmat.2018.06.001.

6. ZHENG C, SHEN H, PU T, et al., High-efficient solar cells by the ag/cu-assisted chemical etching process on diamond-wire-sawn multicrystalline silicon[J]. IEEE Journal of Photovoltaics, 2017, 7(1): 153-156. DOI:10.1109/JPHOTOV.2016.2631304.

7. CHEN K, ZHA J, HU F, et al. MACE nano-texture process applicable for both single- and multicrystalline diamond-wire sawn si solar cells[J]. Solar Energy Materials and Solar Cells, 2019, 191: 1-8. 
DOI:10.1016/j.solmat.2018.10.015.

8. OH J, YUAN H-C, BRANZ H M. An 18.2\%-efficient black-silicon solar cell achieved through control of carrier recombination in nanostructures: 11[J]. Nature Nanotechnology, 2012, 7(11): 743-748. DOI:10.1038/nnano.2012.166. 